\title{
La salud emocional y los resultados académicos
}

\author{
Gaspar Manuel Zavala Taylor
}

\section{Resumen}

$\mathrm{E}$ n la educación de un ser humano existen factores que determinan este proceso. Desde la niñez, los primeros responsables -los padres de familia- son quienes inician dando las bases fundamentales, como los hábitos y el afecto; en una segunda etapa -educación formal-, los niños y jóvenes reciben la formación en conocimientos que los llevará a ir desarrollando sus competencias y habilidades, pues será muy importante que todos los que intervienen en la educación -papás y docentes- sepan estar atentos al desarrollo emocional de los alumnos, al haber una estrecha relación entre el manejo de las emociones y la adquisición del conocimiento.

Palabras clave: emociones, formación, padres de familia, docentes.

\section{Introducción}

La educación media superior es una etapa de formación en la que los jóvenes deberán adquirir las habilidades y aptitudes académicas, psíquicas y físicas para iniciar una carrera de estudios profesionales. En la actualidad, el directivo o docente que colabora en la educación media superior se enfrenta a una doble gran tarea: la primera, formar los conocimientos, habilidades y aptitudes para que un alumno egrese de este nivel con las herramientas necesarias para iniciar una carrera profesional; por otra parte, se tiene que atender de manera importante la inteligencia emocional, pues hay una estrecha relación entre la edad y el coeficiente emocional de los estudiantes (Aguilar, Chávez y Caicedo, 2017). Es en esta etapa donde se conjugan cambios psíquicos y físicos que determinarán la vida madura de la persona. Al hablar de la inteligencia emocional de los alumnos, se tiene que considerar en todo momento el entorno familiar, pues es en la familia donde, desde los primeros años, se van formando las emociones; de ahí que sea muy importante conocer e involucrar, lo más que se pueda, a los padres o tutores del alumno en esta última etapa de la educación obligatoria.

\section{Desarrollo}

En los últimos años, los sistemas educativos en el mundo han cambiado de manera importante. Una de las razones principales es la revolución tecnológica y la globalización que se vive en el mundo. Los niños y jóvenes conocen y aprenden de diferente manera a la de hace 20 años; hoy, el internet es una herramienta que permite acceder a la información de una manera vertiginosa, lo que ha cambiado los esquemas de educación en el mundo. Una muestra de estos cambios es que en nuestro país se han tenido modificaciones constantes en los planes y modelos de todos los niveles de educación escolar, con el objetivo de ofrecer una forma de educación más accesible y de mejor calidad, para lograr con esto mejores resultados en evaluaciones internacionales, como la de PISA (Programa para la Evaluación Internacional de Alumnos) (INEE, 2018).

Estos cambios en los sistemas de educación en nuestro país ofrecen al docente la posibilidad de acceder a nuevas y diversas formas para facilitar el conocimiento, evaluar a los alumnos y generar un buen desarrollo de las competencias que requerirán para seguir con una preparación profesional. Para ello, será muy importante que el docente esté abierto a conocer y/o aprender estas nuevas formas de los procesos de enseñanza y aprendizaje, así como a sensibilizarse en los diversos esquemas de evaluación que ofrecen estos nuevos sistemas.

$\mathrm{Al}$ igual que los modelos y/o sistemas, las instituciones educativas han evolucionado en el mundo; también se ha modificado el esquema para que los padres de familia sepan cómo hacer frente a la tarea de formar a sus hijos. En mi experiencia como directivo y profesor de 
instituciones de educación media superior, he observado que algunos padres de familia viven en cierta "crisis" al no saber cómo enfrentar el mundo de los adolescentes y jóvenes que están creciendo en un entorno de tecnología, cambios económicos, políticos, sociales, religiosos y de globalización. En ese sentido, Patricia Prieto (2015) refiere el estudio "Social media, social life-teens reveal their experiences" (2018), realizado por Common Sense Media, donde se

[...] encontró que en un día cualquiera los adolescentes y preadolescentes de este país [Estados Unidos de América] gastan cerca de nueve horas con los medios tecnológicos y sociales. Es decir que el tiempo que dedican a las redes sociales y a televisores, videojuegos y otros aparatos electrónicos es mayor que el [que] pasan durmiendo o interrelacionándose con sus padres y profesores. Una cifra alarmante que el reporte reveló, por ejemplo, es que algunos niños de 13 años revisan 100 veces al día su Facebook o Instagram (u otro medio social) para saber qué están diciendo sus amigos sobre ellos.

Ahora algunos padres de familia, en ocasiones, están inmersos y dedican más tiempo a resolver diversas situaciones como el trabajo, lo que conlleva a una falta de atención a aspectos fundamentales en la educación de los hijos, como la formación de virtudes, entre las que destacan el respeto, la responsabilidad, el orden, la templanza, el pudor, la fortaleza, la solidaridad, entre otras de trascendencia para la vida.

Por otra parte, dentro de esta formación que se debe dar en casa, los padres de familia, y primeros responsables (como idea óptima), además de tener una cierta estabilidad emocional, deberán ser conscientes de que cada acción que ellos realicen con sus hijos está formando y/o afectando positiva o negativamente sus emociones. En ese sentido, Ader (2007, en Bisquerra, 2009: 161) dice: "Las aportaciones de la psiconeuroinmunología aportan evidencias de que las emociones afectan al sistema inmunitario. Las emociones negativas debilitan las defensas del sistema inmunitario, mientras que las emociones positivas lo refuerzan". Desde los primeros años de vida, son los padres quienes las forman con acciones donde se genere la confianza, la comunicación, los vínculos afectivos, entre otros aspectos que serán vitales para la autoestima y las que, por consiguiente, formarán una inteligencia emocional sana en los hijos, como lo cita Daniel Goleman (1999: 122) en su libro La inteligencia emocional:
El impacto en los hijos de los progenitores emocionalmente competentes es ciertamente extraordinario. El equipo de la Universidad de Washington que antes mencionamos descubrió que los hijos de padres emocionalmente diestros -comparados con los hijos de aquéllos otros que tienen un pobre manejo de sus sentimientos- se relacionan mejor, experimentan menos tensiones en la relación con sus padres y también se muestran más afectivos con ellos. Pero, además, estos niños también canalizan mejor sus emociones, saben calmarse más adecuadamente a sí mismos y sufren menos altibajos emocionales que los demás.

Ante esto, se considera por la propia experiencia como consultor que son pocos los padres de familia que tienen el hábito de formarse como papás, de acceder a especialistas, asistir a cursos de formación a las escuelas, leer libros o artículos que los lleven a tener mejor conocimiento de cómo ir abordando cada una de las etapas de formación de los hijos y de cada hijo; pues se debe tener conciencia de que cada ser humano es único y diferente, por ello, cada uno requerirá un tiempo, una manera única para ser formado. De esta manera, hay gran cantidad de medios para que los padres de familia se formen, las mismas escuelas en sus distintos niveles ofrecen cursos de formación como "escuela para padres"; hay organizaciones que apoyan con asesorías, o instituciones públicas en donde las cabezas de familia pueden acceder para recibir apoyo en casos donde tienen dificultades con la educación de los hijos.

Por lo anterior, se identifica como área de oportunidad la de mejorar la participación de los padres de familia en las actividades escolares de sus hijos, pues se ha observado poca participación en los diversos eventos realizados; considerando la cantidad de asistentes frente al total de padres registrados por la institución. Lo anterior podría evitar un "divorcio de mutuo acuerdo" entre la escuela y los padres de familia, como lo expresan James y Guzmán (2016).

Actualmente, en instituciones educativas existen áreas o departamentos de atención psicológica o psicopedagógica que conforman una parte importante para la atención de aquellos alumnos que manifiestan ciertas conductas que no son las que se esperan de un adolescente o joven en la escuela, o bien, presentan alguna dificultad de aprendizaje. Sin embargo, la actitud de observación o alerta que puedan tener los docentes de las materias académicas en el comportamiento diario de los alumnos, en clase y en los momentos de esparcimiento, ayudará significativamente para darse cuenta si un alumno está te- 
niendo alguna dificultad emocional. Debido a lo anterior, Vázquez (2012: 137) encontró "la existencia de una relación positiva y significativa entre la inteligencia emocional y el rendimiento académico".

Por lo mismo, se considera importante que en las escuelas se cuente con planes de capacitación para los docentes y el personal en general, en temas de desarrollo humano, inteligencias múltiples, educación familiar, formación de virtudes, entre otros, que ayudarán de manera significativa para que los docentes tengan mejor desarrollada la habilidad de detectar cuando un estudiante está pasando por alguna situación personal/emocional que afecte negativamente en su rendimiento escolar. La capacitación que se les pueda ofrecer a los docentes de las instituciones educativas en los temas que se mencionan, además de ayudar al alumno, será de gran apoyo para que colaboren de manera más cercana y asertiva con los padres de familia y se haga una mancuerna en la que juntos atiendan las situaciones particulares de los alumnos/hijos.

\section{Conclusiones}

Se considera que cuando se tienen docentes formados y con una adecuada salud emocional es más fácil generar un programa de atención y seguimiento personalizado, en donde a los padres de familia se les pueda pedir de manera regular asistir a la escuela para darle un seguimiento al desempeño general del alumno y con ello poder hablar de una comunión entre docentes y padres de familia, y no un "divorcio de mutuo consentimiento", como se mencionó anteriormente.

Establecer planes que estén enfocados en el alumno en donde, además de él, participan de forma activa los papás y los docentes, es una manera de fortalecer su formación emocional y autoestima para impulsarlos a lograr mejores resultados académicos. Hoy la educación en el bachillerato debe incorporar planes realmente efectivos en donde los padres de familia participen de una manera más activa en el proceso de la formación humana y académica de los alumnos; desafortunadamente en la educación media superior algunos padres de familia tienden a desligarse del proceso educativo de sus hijos; no obstante, la preparatoria es la etapa en la que se terminan de formar aspectos fundamentales del carácter y de la preparación académica, que les ayudarán a tomar decisiones que determinarán su vida adulta, como la carrera de estudios, planes de trabajo y cambios de residencia, entre otras.

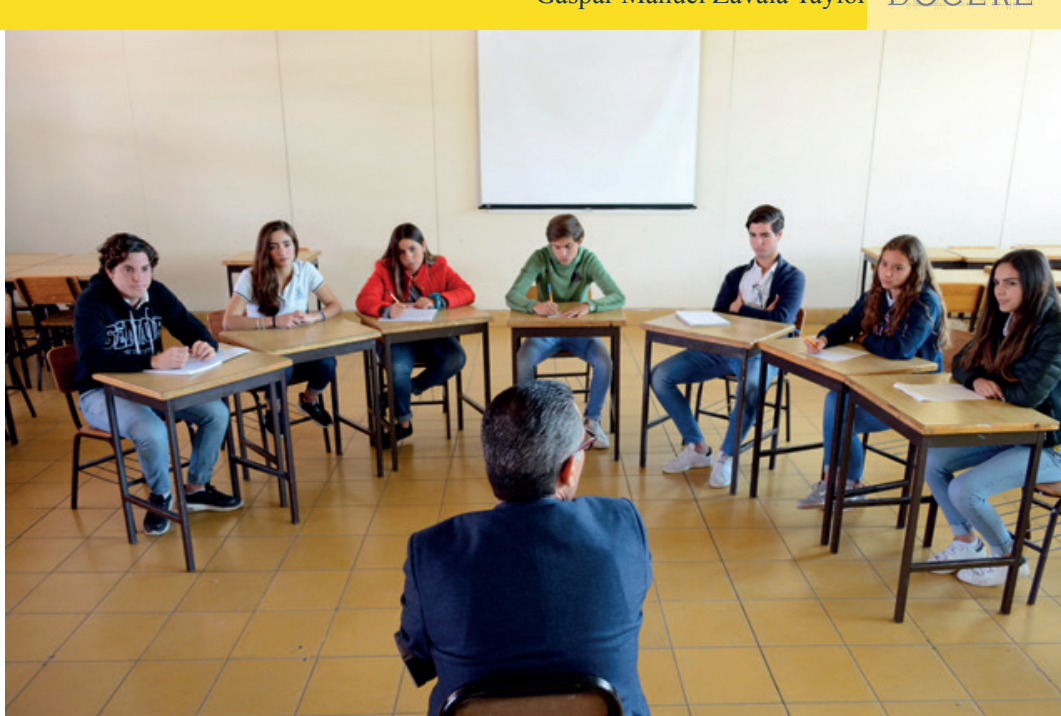

《 Hoy la educación en el bachillerato debe incorporar planes realmente efectivos en donde los padres de familia participen. $\gg$

\section{Fuentes de consulta}

Aguilar, J., Chávez, C. y Caicedo, I. (2017). Inteligencia emocional en estudiantes de bachillerato pertenecientes a los países de México y Ecuador. Congreso Nacional de Investigación Educativa COMIE. Recuperado de: http://www.comie.org.mx/congreso/memoriaelectronica/v14/doc/1775.pdf.

Bisquerra, R. (2009). Psicopedagogía de las emociones. Madrid: Síntesis.

Goleman, D. (1999). La inteligencia emocional. Barcelona: Kairós.

INEE (2018). Evaluaciones internacionales. ¿Qué es PISA? México: Instituto Nacional para la Evaluación de la Educación (INEE). Recuperado de: https://www. inee.edu.mx/index.php/evaluaciones-internacionales/que-es-pisa-2016.

James, C. y Guzmán, E. (2016). La participación de madres y padres de familia en la escuela: un divorcio de mutuo consentimiento. Sinéctica, (46). Recuperado de: https://sinectica.iteso.mx/index.php/ SINECTICA/article/view/610.

Prieto, P. (2015). Familias: ¿Unidas o separadas por la tecnología? La Opinión. Recuperado de: https:// laopinion.com/2015/12/09/unidos-o-separadospor-la-tecnologia/.

Vázquez, J. (2012). Inteligencia emocional y rendimiento académico en estudiantes adolescentes. México: Universidad Pedagógica Nacional. Recuperado de: http://200.23.113.51/pdf/29436.pdf. 